Article

\title{
Combined Effects of Ethnicity and Education on Burden of Depressive Symptoms over 24 Years in Middle-Aged and Older Adults in the United States
}

\author{
Shervin Assari ${ }^{\mathbb{D}}$ \\ Department of Family Medicine, Charles R. Drew University of Medicine and Science, \\ Los Angeles, CA 90095, USA; assari@umich.edu; Tel.: +1-734-232-0445; Fax: +1-734-615-8739
}

Received: 4 March 2020; Accepted: 30 March 2020; Published: 2 April 2020

\begin{abstract}
Ethnicity and educational attainment are among the major social determinants of depression in the general population. While high education credentials protect individuals against depressive symptoms, this protection may be weaker for ethnic minority groups such as Hispanic Whites compared to the majority group (non-Hispanic Whites). Built on marginalization-related diminished returns (MDRs), the current study used 24-year follow-up data from a nationally representative sample of middle-aged and older adults to explore ethnic variation in the protective effect of education levels against the burden of depressive symptoms over time. Data for this analysis were borrowed from the Health and Retirement Study (HRS 1992-ongoing), a nationally representative longitudinal study. HRS followed 8314 middle-aged and older adults (50+ years old) for up to 24 years. From this number, 763 (9.2\%) were Hispanic White, and 7551 (90.8\%) were non-Hispanic White Americans. Education level was the independent variable. We had two outcomes. Firstly, using cluster analysis, individuals were categorized to low- and high-risk groups (regarding the burden of depressive symptoms over 24 years); secondly, average depressive symptoms were observed over the 24 years of follow up. Age and gender were the covariates. Ethnicity was the moderator. Linear and logistic regression were used for analysis. Logistic regression showed that, overall, high educational credentials reduced the odds of chronic depressive symptoms over the 24 years of follow-up. Linear regression also showed that higher years of education were associated with lower average depressive symptoms over time. Both models showed statistically significant interactions between ethnicity and graduation, indicating a smaller protective effect of high education against depressive symptoms over the 24 years of follow-up time among Hispanic with respect to non-Hispanic White people. In line with the MDRs, highly educated Hispanic White Americans remain at high risk for depressive symptoms, a risk that is unexpected given their education. The burden of depressive symptoms, however, is lowest for highly educated non-Hispanic White Americans. Policies that exclusively focus on equalizing educational gaps across ethnic groups may fail to eliminate the ethnic gap in the burden of chronic depressive symptoms, given the diminished marginal health return of education for ethnic minorities. Public policies must equalize not only education but also educational quality across ethnic groups. This aim would require addressing structural and environmental barriers that are disproportionately more common in the lives of ethnic minorities across education levels. Future research should test how contextual factors, residential segregation, school segregation, labor market practices, childhood poverty, and education quality in urban schools reduce the health return of educational attainment for highly educated ethnic minorities such as Hispanics.
\end{abstract}

Keywords: socioeconomic position; socioeconomic status; educational attainment; race; ethnic groups; Latino; Hispanic 


\section{Introduction}

Socioeconomic status is among the significant determinants of mental health outcomes [1-5], including but not limited to clinical depression [6-11] and depressive symptoms [6,12-14]. Individuals with higher educational attainment are protected against the risk of mental health problems [1,2] such as depression [14-16]. These studies are, however, predominantly cross-sectional or, if longitudinal, they have short follow-up periods. In addition, very little is known about the relevance of socioeconomic status (SES), particularly education, to the mental health of middle-aged and older adults.

High SES, however, differently impacts the mental and physical health of sub-populations $[17,18]$. For example, education [19], employment [20,21], marital status [22], and income [23] show smaller health effects for ethnic minorities than non-Hispanic White individuals. As a result, middle-class ethnic minorities [23] may remain at high risk of health risk behaviors [24] and depression [25-30]. Whether these diminished returns of education on various health outcomes remain in middle-aged and older adults and whether these patterns remain the same over a long period are still unclear [31]. Most of this literature is on the comparison of non-Hispanic Whites and non-Hispanic Blacks, and less is known about comparisons between Hispanics and non-Hispanics [32-34]. Moreover, almost nothing is known on how Hispanic and non-Hispanic older adults vary in the long-term effects of education on the burden of depressive symptoms.

\subsection{Marginalization-Related Diminished Returns (MDRs)}

According to the MDRs $[17,18]$, health effects of SES indicators, particularly educational attainment, are systematically weaker on the members of socially marginalized groups in comparison to the members of socially privileged groups. This is mainly established for the comparison of non-Hispanic Blacks relative to Whites (the majority group). Research shows that educational attainment generates worse employment conditions and lower income $[1,2,35][21,36]$ for the members of ethnic minority groups compared to non-Hispanic Whites. Education attainment also better reduces environmental exposures for non-Hispanic Whites than ethnic minorities [21,37]. As a result, middle-class ethnic minority individuals who have access to high education [38], employment [39], marital status [40], and income [23] remain at risk of mental health problems.

As a result of these MDRs, highly educated ethnic minorities remain at risk of low exercise [41], unhealthy diet [42], alcohol use, poor school performance [24], aggression [24], tobacco use [24], health service use [43], stress [20,21,30], anxiety [22], depression [26,44], and suicide [45]. As a result, the health of middle-class ethnic minority groups still suffers despite having access to SES resources. It was shown that the effects of various SES indicators such as education [26,46], marital status [40], and employment [47] on various health outcomes are all weaker for ethnic minorities than non-Hispanic Whites. Similarly, education better reduces the risk of hospitalization [33] and disability [48] for non-Hispanic Whites than ethnic minorities. Similarly, education and income better reduce the risk of depression [26] for non-Hispanic Whites than ethnic minorities. It is, however, unknown if these effects remain stable over long periods. Furthermore, while most research is done on adolescents and younger adults, there is a need to test whether such patterns hold up among older adults.

\subsection{Mechanisms of MDRs}

Many potential explanations exist for why education shows smaller health effects for ethnic minorities than non-Hispanic Whites. Poor quality of education in predominantly minority communities is one explanation for the MDRs of education for these populations [49-52]. Manly and colleagues suggested that poor quality of schooling and education may partially explain some of the ethnic differences in the protective effects of education on conditions such as Alzheimer's disease [51,53-56]. We also found that education and education quality, as well as school bonding [57] and educational mobility $[19,58,59]$, may all have some role in this phenomenon. 
Another explanation of the MDRs phenomenon is the labor market discrimination of ethnic minorities [36,60]. MDRs of education on health may be because of the MDRs of education in the labor market in generating income and wealth $[35,61,62]$. We know that high education level has a smaller effect on reducing the risk of poverty among ethnic minorities, compared to non-Hispanic White Americans [35,61]. As a result of labor market discrimination, highly educated ethnic minorities work in low-quality and stressful jobs [21,62]. Such conditions increase the environmental exposure of highly educated ethnic minorities with respect to non-Hispanic White people to environmental exposures with serious health hazards $[21,37,60,63]$.

Another mechanism is interpersonal discrimination. High-SES ethnic minorities face and report more, not less discrimination $[9,13,14,64]$. High SES also increases vulnerability to discrimination [65]. In a study, high-SES ethnic minorities were more likely to develop depression as a result of discrimination [65]. This might be, in part, because highly educated people are more likely to be surrounded by White people, across all ethnic groups. This increased exposure to White people increases their exposure to perceived discrimination and prejudice $[28,29,66,67]$.

\subsection{Aims}

To better understand whether the MDRs phenomenon also applies to ethnic disparities in the burden of depressive symptoms over a long period, we compared non-Hispanic and Hispanic White middle-aged and older Americans for the protective effect of education level on chronic depressive symptoms over 24 years of follow-up. Although research thoroughly documented the additive effects of ethnicity and SES (education level) on long-term health outcomes [68,69], very few studies ever tested MDRs of educational attainment on morbidity over a long period of time [70]. Such a study would require studying the non-additive and multiplicative effects of ethnicity and educational attainment on long-term data on various aspects of health. Such an approach would require long-term data with follow-up of health over a long period. We used data from the Health and Retirement Study (HRS), an ongoing study with a national and representative sample of middle-aged and older adults (50-59 years old at baseline). In line with the MDRs [17,18], we expected smaller protective effects of education level on the burden of depressive symptoms over time for Hispanic compared to non-Hispanic White Americans.

Built on the Health and Retirement Study (HRS) data, this study explored ethnic variation in the effects of educational attainment and income on a 24-year life expectancy of middle-aged and older American adults. In concordance with the MDRs framework [17,71], we expected weaker effects of baseline educational credentials on the long-term burden of depressive symptoms of Hispanic White middle-aged and older adults in comparison to their non-Hispanic White counterparts. In other terms, we expected a disproportionately high level of chronic depressive symptoms in highly educated Hispanic White middle-aged and older adults. However, we expected the lowest level of burden of depressive symptoms over time for highly educated non-Hispanic White middle-aged and older adults.

\section{Methods}

\subsection{Design and Setting}

Data came from the first 10 waves of the Health and Retirement Study (HRS, 1992-ongoing). The HRS is a long-term longitudinal study, with biannual repeated measurements. The study recruited and followed a nationally representative sample of American middle-aged and older adults (age 50-59 years at baseline). Although more detailed methodological information exists on study design, measures, sample, and sampling of the HRS [72], we provide a summary of the critical aspects of the HRS. 


\subsection{Sample and Sampling}

The HRS used a national area probability sampling to recruit participants. The current analysis only included the core (primary) sample that was recruited in 1992. All participants were 50-59 years old at wave one. This means that all our participants were born between 1931 and 1941. The HRS sample is representative of all 50-59-year-old middle-aged and older adults who resided in United States (US) households in 1992 (Wave 1).

\subsection{Analytical Sample}

The analytical sample of the current study involved 50+ years old Americans who were non-Hispanic or Hispanic White. Only White people were enrolled in our analysis; thus, all Black people were excluded. All participants in the HRS core sample could enter our analysis regardless of the duration of follow-up because our outcome was time from follow-up to mortality. Thus, participants were analyzed only if they were non-Hispanic or Hispanic White $(n=8314)$.

\subsection{Data Collection}

The HRS study collected data that extended to various aspects of the participants. This data collection included demographic information, SES indicators, social factors, psychological assets and traits, health behaviors, health service utilization, and objective and subjective measures of health. While HRS collected data from both participants and their spouses, we only used the participants' data. Data were collected biannually. The HRS data were collected via either telephone or a face-to-face interview. For individuals who were not available themselves, a proxy interview was used.

\subsection{Measures}

Demographic Factors. Age (years) and gender (0/1) were demographic factors. Age was a continuous measure (recorded as the number of years passed since birth). Gender was a dichotomous variable, coded as male $=1$, female $=0$. Age and gender were both measured in 1992 .

Socioeconomic Status (SES) Indicator. In this study, educational attainment was treated in two ways: firstly, as a categorical variable: (1) less than high-school diploma (reference group), (2) high-school diploma, (3) some college, and (4) college graduate; secondly, as a continuous measure. For education as a continuous measure, we used years of schooling, which was measured at baseline (1992). The categorical variable was entered into our logistic regressions, and the continuous variable was entered into our linear regressions.

Depressive Symptoms. HRS used the eight-item Center for Epidemiological Studies Depression (CES-D) measure to assess depressive symptoms. Items were on a 0/1 response scale. Depressive symptoms were measured every two years, from 1994 to 2016. For this variable as a continuous measure, we calculated the mean score over time. For this measure as a categorical/binary variable, we used k-mean cluster analysis to define risk categories over the 24 years of follow-up (the first wave did not have depressive symptoms). The categorical variable was entered into our logistic regressions, and the continuous variable was entered into our linear regressions.

\subsection{Data Analysis}

We analyzed the HRS data using SPSS 23.0 (IBM Corporation, Armonk, NY, US). For our univariate analyses, means (standard deviation: SD) and absolute/relative frequencies ( $n$ and \%) were reported. We calculated two outcomes: firstly, a binary (categorical) variable, and secondly, a continuous measure. To define our binary (categorical) outcome, we used k-mean cluster analysis with all observations of depressive symptoms $(n=12)$ as input variables. Using this approach, participants were categorized as low-risk (coded as 0 ) or high-risk (coded as 1) groups. Our continuous outcome was mean depressive symptoms over the follow-up period. For multivariable analysis of our binary (categorical) outcome, we applied logistic regressions. For our continuous measure, we ran linear regression 
models. Our modeling strategies remained similar; however, years of education and educational credentials were the outcomes for linear regression and logistic regression, respectively. In these models, membership of the cluster of chronic depressive symptoms was considered as binary outcomes. Firstly, we ruled out multi-collinearity between ethnicity and educational attainment. We did not have any missing data for our outcomes because individuals could become a member of a cluster group regardless of the number of observations and missing data. We ran 12 logistic regression models, three for each outcome: Model 1 was without interaction in the pooled sample, Model 2 was with the statistical interaction terms between ethnicity and educational attainment in the pooled sample, Model 3 was in non-Hispanic White people, and Model 4 was in Hispanic White people.

\subsection{Ethics Statement}

The HRS study protocol was approved by the University of Michigan (UM) Institutional Review Board (IRB). All HRS participants signed written consent. The data were collected, stored, managed, and analyzed in a fully anonymous fashion. As we used fully de-identified publicly available data, this study was non-human subject research, according to the National Institutes of Health (NIH) definition.

\section{Results}

\subsection{Descriptives}

This analysis included a total of 8314 middle-aged and older adults (50+ years old) who were followed for 24 years. From this number, 763 (9.2\%) were Hispanic White, and 7551 (90.8\%) were non-Hispanic White Americans.

Table 1 presents a summary of the descriptive characteristics of the overall sample and by ethnicity. As this table shows, Hispanics had lower education but were more likely to be in the chronic depressed group. They also had higher average depressive symptoms over the 24 years of follow-up.

Table 1. Descriptive statistics $(n=8314)$.

\begin{tabular}{|c|c|c|c|c|c|c|}
\hline Characteristics & All & & $\begin{array}{l}\text { Non-Hispanic } \\
\text { Whites }\end{array}$ & & $\begin{array}{c}\text { Hispanic } \\
\text { Whites }\end{array}$ & \\
\hline & Mean & SD & Mean & SD & Mean & SD \\
\hline Age (years) & 56.42 & 4.43 & 56.43 & 4.38 & 56.34 & 4.83 \\
\hline \multirow[t]{2}{*}{$\begin{array}{c}\text { Average depressive symptoms } \\
\text { over time * }\end{array}$} & 1.38 & 1.52 & 1.29 & 1.44 & 2.24 & 1.92 \\
\hline & $N$ & $\%$ & $N$ & $\%$ & $N$ & $\%$ \\
\hline \multicolumn{7}{|l|}{ Ethnicity } \\
\hline Non-Hispanic & 7551 & 90.8 & 7551 & 100.0 & - & - \\
\hline Hispanic & 763 & 9.2 & - & - & 763 & 100.0 \\
\hline \multicolumn{7}{|l|}{ Gender } \\
\hline Female & 4132 & 49.7 & 3733 & 49.4 & 399 & 52.3 \\
\hline Male & 4182 & 50.3 & 3818 & 50.6 & 364 & 47.7 \\
\hline \multicolumn{7}{|l|}{ Education * } \\
\hline Less than high-school diploma & 1893 & 22.8 & 1422 & 18.8 & 471 & 61.7 \\
\hline High-school diploma & 3276 & 39.4 & 3118 & 41.3 & 158 & 20.7 \\
\hline Some college & 1632 & 19.6 & 1536 & 20.3 & 96 & 12.6 \\
\hline College graduate & 1513 & 18.2 & 1475 & 19.5 & 38 & 5.0 \\
\hline \multicolumn{7}{|l|}{ High depressive symptoms * } \\
\hline No & 6609 & 79.5 & 6149 & 81.4 & 460 & 60.3 \\
\hline Yes & 1705 & 20.5 & 1402 & 18.6 & 303 & 39.7 \\
\hline
\end{tabular}

\subsection{Logistic Regressions}

Table 2 summarizes the results of two logistic regressions with chronic depressive symptoms over 24 years as the outcome. Model 1- $a$ was without interactions (main effects model), while Model 2- $a$ (main effects + interaction model) had statistical interactions between levels of educational attainment and 
ethnicity. Model 1- $a$ showed that, overall, higher education credentials are associated with lower odds of chronic depressive symptoms over the 24 years of follow-up, while all confounders were controlled. Model 2- $a$ showed a statistically significant interaction between the effects of ethnicity and college graduation on the outcome, suggesting that the protective effect of college graduation against the risk of chronic depressive symptoms was smaller for Hispanic White than non-Hispanic White Americans.

Table 2. Pooled sample and ethnic-specific logistic regressions of depressive symptoms over 24 years. $\mathrm{OR}$-odds ratio; $\mathrm{CI}$-confidence interval.

\begin{tabular}{|c|c|c|c|c|c|c|c|c|}
\hline \multirow[b]{3}{*}{ Ethnicity (Hispanic) * } & \multicolumn{4}{|c|}{$\begin{array}{c}\text { Model 1- } a \\
\text { (Main Effects) }\end{array}$} & \multicolumn{4}{|c|}{$\begin{array}{c}\text { Model 2- } a \\
\text { (Main Effects + Interactions) }\end{array}$} \\
\hline & \multirow{2}{*}{$\begin{array}{c}\text { OR } \\
1.85\end{array}$} & \multicolumn{2}{|c|}{$95 \%$ CI } & \multirow{2}{*}{$\begin{array}{c}p \\
<0.001\end{array}$} & \multirow{2}{*}{$\begin{array}{c}\text { OR } \\
0.70\end{array}$} & \multicolumn{2}{|c|}{$95 \%$ CI } & \multirow{2}{*}{$\begin{array}{c}p \\
<0.001\end{array}$} \\
\hline & & 1.56 & 2.19 & & & 0.62 & 0.78 & \\
\hline Gender (male)* & 0.70 & 0.62 & 0.78 & $<0.001$ & 1.63 & 1.31 & 2.01 & $<0.001$ \\
\hline Age (years) & 1.00 & 0.99 & 1.01 & 0.935 & 1.00 & 0.99 & 1.01 & 0.931 \\
\hline Education & & & & $<0.001$ & & & & $<0.001$ \\
\hline Less than high-school diploma & 1.00 & & & & 1.00 & & & \\
\hline High-school diploma * & 0.44 & 0.38 & 0.50 & $<0.001$ & 0.42 & 0.36 & 0.48 & $<0.001$ \\
\hline Some college $*$ & 0.33 & 0.28 & 0.39 & $<0.001$ & 0.32 & 0.26 & 0.38 & $<0.001$ \\
\hline College graduate ${ }^{*}$ & 0.20 & 0.16 & 0.24 & $<0.001$ & 0.18 & 0.15 & 0.23 & $<0.001$ \\
\hline Education $\times$ ethnicity & & & & & & & & 0.062 \\
\hline High-school diploma $\times$ ethnicity & - & - & - & - & 1.28 & 0.85 & 1.92 & 0.244 \\
\hline Some college $\times$ ethnicity & - & - & - & - & 1.30 & 0.77 & 2.20 & 0.320 \\
\hline College $\times$ ethnicity ${ }^{*}$ & - & - & - & - & 2.65 & 1.24 & 5.66 & 0.012 \\
\hline Intercept & 0.58 & & & 0.149 & 0.60 & & & 0.175 \\
\hline
\end{tabular}

OR $=$ Odds Ratio, $\mathrm{CI}=$ Confidence Interval, ${ }^{*} p<0.05$.

Table 3 also summarizes the results of two identical ethnic-specific logistic regression models. Model 3- $a$ was performed in non-Hispanic White Americans, and Model 4- $a$ was performed in Hispanic White Americans. Model 3- $a$ and Model 4- $a$ showed that college graduation was associated with lower odds of chronic depressive symptoms over 24 years for non-Hispanic White but not Hispanic White Americans (Table 3).

Table 3. Ethnic-specific logistic regressions for chronic depressive symptoms as the outcome.

\begin{tabular}{ccccccccc}
\hline & \multicolumn{3}{c}{$\begin{array}{c}\text { Model 3-a } \\
\text { Non-Hispanic }\end{array}$} & \multicolumn{5}{c}{$\begin{array}{c}\text { Model 4-a } \\
\text { Hispanic }\end{array}$} \\
\cline { 2 - 10 } & OR & \multicolumn{9}{c}{$\mathbf{9 5 \%}$ CI } & $p$ & OR & $\mathbf{9 5 \% ~ C I ~}$ & $p$ \\
\hline Gender (male) * & 0.72 & 0.64 & 0.82 & $<0.001$ & 0.55 & 0.41 & 0.75 & $<0.001$ \\
Age (years) & 1.00 & 0.99 & 1.02 & 0.735 & 0.99 & 0.96 & 1.02 & 0.638 \\
Education & & & & $<0.001$ & & & & $<0.001$ \\
Less than high-school diploma & 1.00 & & & & 1.00 & & & \\
High-school diploma * & 0.42 & 0.36 & 0.49 & $<0.001$ & 0.54 & 0.36 & 0.79 & 0.002 \\
$\quad$ Some college * & 0.32 & 0.26 & 0.38 & $<0.001$ & 0.41 & 0.25 & 0.67 & $<0.001$ \\
College graduate * & 0.18 & 0.15 & 0.23 & $<0.001$ & 0.49 & 0.24 & 1.02 & 0.058 \\
$\quad$ Intercept & 0.53 & & & 0.122 & 1.74 & & & 0.550 \\
\hline
\end{tabular}

OR $=$ Odds Ratio, $\mathrm{CI}=$ Confidence Interval, ${ }^{*} p<0.05$

\subsection{Sensitivity Analysis}

To run some sensitivity analyses, we also ran linear regression models with mean depressive symptoms over the 24 years of follow-up as the outcome. Our modeling strategy stayed the same as our main logistic regression models. Firstly, we ran two linear regressions with mean depressive symptoms over 24 years as the outcome. Model 1-b was without interactions (main effects model), while Model 2 (main effects + interaction model) had a statistical interaction between years of schooling (educational attainment) and ethnicity. Model 1 showed that, overall, a higher number of years of schooling (educational attainment) was associated with lower mean depressive symptoms over the 
24 years of follow-up, while all confounders were controlled. Model 2-b showed a statistically significant interaction between the effects of ethnicity and years of schooling on the outcome, suggesting that the protective effect of higher number of years of schooling against mean depressive symptoms over time was smaller for Hispanic White than non-Hispanic White Americans. We also ran two identical ethnic-specific linear regression models. Model $3-b$ was performed in non-Hispanic White Americans, and Model $4-b$ was performed in Hispanic White Americans. Model 3-b and Model 4-b showed that a higher number of years of schooling was associated with lower mean depressive symptoms over 24 years for non-Hispanic White and Hispanic White Americans; however, the magnitude of this protection was larger for non-Hispanic White than Hispanic White Americans (Tables 4 and 5).

Table 4. Pooled sample linear regressions for mean depressive symptoms over 24 years as the outcome.

\begin{tabular}{|c|c|c|c|c|c|c|c|c|}
\hline \multirow[b]{3}{*}{ Ethnicity (Hispanic)* } & \multicolumn{3}{|c|}{$\begin{array}{l}\text { Mode } \\
\text { 1-b }\end{array}$} & \multicolumn{5}{|c|}{$\begin{array}{l}\text { Mode } \\
\text { 2-b }\end{array}$} \\
\hline & \multirow{2}{*}{$\begin{array}{c}\mathbf{b} \\
0.41\end{array}$} & \multicolumn{2}{|c|}{$95 \% \mathrm{CI}$} & \multirow{2}{*}{$\begin{array}{c}p \\
0.000\end{array}$} & \multirow{2}{*}{$\begin{array}{c}\mathbf{b} \\
-0.08\end{array}$} & \multicolumn{2}{|c|}{$95 \% \mathrm{CI}$} & \multirow{2}{*}{$\begin{array}{c}p \\
0.576\end{array}$} \\
\hline & & 0.29 & 0.52 & & & -0.34 & 0.19 & \\
\hline Gender (male) * & -0.32 & -0.38 & -0.25 & 0.000 & -0.32 & -0.38 & -0.25 & 0.000 \\
\hline Age (years) & 0.00 & 0.00 & 0.01 & 0.384 & 0.00 & 0.00 & 0.01 & 0.387 \\
\hline Education * & -0.13 & -0.14 & -0.12 & 0.000 & -0.14 & -0.15 & -0.13 & 0.000 \\
\hline Education $\times$ ethnicity * & & & & & 0.05 & 0.03 & 0.08 & 0.000 \\
\hline Intercept ${ }^{*}$ & 2.90 & 2.46 & 3.33 & 0.000 & 3.04 & 2.61 & 3.48 & 0.000 \\
\hline
\end{tabular}

$\mathrm{CI}=$ Confidence Interval, $\mathbf{b}=$ unstandardized regression coefficient, ${ }^{*} p<0.05$.

Table 5. Ethnic-specific linear regressions for mean depressive symptoms over 24 years as the outcome.

\begin{tabular}{ccccccccc}
\hline & $\begin{array}{c}\text { Model } \\
\text { 3-b } \\
\text { Non-Hispanic }\end{array}$ & \multicolumn{5}{c}{$\begin{array}{c}\text { Model } \\
\text { 4-b } \\
\text { Hispanic }\end{array}$} \\
& $\mathbf{b}$ & \multicolumn{2}{c}{$\mathbf{9 5 \%}$ CI } & $\boldsymbol{p}$ & $\mathbf{b}$ & $\mathbf{9 5 \%}$ CI & $\boldsymbol{p}$ \\
\hline Gender (male) * $^{\text {b }}$ & -0.27 & -0.34 & -0.21 & 0.000 & -0.73 & -1.00 & -0.46 & 0.000 \\
Age (years) & 0.00 & 0.00 & 0.01 & 0.209 & -0.01 & -0.04 & 0.02 & 0.625 \\
Education * $^{\text {Intercept * }}$ & -0.14 & -0.15 & -0.13 & 0.000 & -0.09 & -0.12 & -0.06 & 0.000 \\
& 2.94 & 2.49 & 3.38 & 0.000 & 3.72 & 2.11 & 5.33 & 0.000 \\
\hline
\end{tabular}

$\mathrm{CI}=$ Confidence Interval, $\mathbf{b}=$ unstandardized regression coefficient, ${ }^{*} p<0.05$.

\section{Discussion}

This study documented two main findings. Firstly, high education level at baseline was associated with better health status over 24 years of follow-up in the overall sample. Secondly, compared to non-Hispanic White Americans, Hispanic White Americans remained at a relative disadvantage regarding the protective effects of education level on various aspects of health. That is because the inverse association between education level and various aspects of morbidity is weaker for Hispanic than non-Hispanic White middle-aged and older Americans.

The first finding is an extension of previous research. While we know that population health improves as education level and SES improve, most of the literature on social determinants of health and social gradient in health was conducted using a cross-sectional design or, if longitudinal, a short-term follow-up period. The protective health effect of SES, particularly education level, is well established in the literature [73-75]. The social gradient of health is well known [76,77]. Each additional year of schooling has a protective effect on health $[73,74]$. Similarly, educational credentials have some protective effects $[73,74]$. Overall, morbidity and mortality are more common at the bottom of society, which is closely linked to SES and education [78-83].

The second finding is also an extension of what we knew from cross-sectional or short-term follow-up studies. Studies by Navarro [84-86] and Farmer and Ferarro [87] mentioned that it is ethnicity and SES, but not ethnicity or SES, that cause disparities. Our previous research also 
documented the considerably weaker impact of education and other SES indicators on the well-being of ethnic minorities other than non-Hispanic White Americans [17,71]. In various studies, education more strongly improved overall health [32,62,88], impulsivity [89], drinking [46,90], smoking [91,92], sleep [93], exercise [41], suicide [45], and depression [6,28,44] for non-Hispanic White Americans than ethnic minority Americans. These patterns are robust, as shown for Hispanics [94], non-Hispanic Blacks [95,96], Native Americans [36], East Asians [97,98], and members of the LGBT community [99]. This universal pattern suggests that MDRs are not due to the group or individual behaviors but due to structural and societal processes that hinder individuals' and populations' ability to leverage their education and other SES indicators [17,71]. Although these patterns are seen for all non-privileged groups, they are more robust for Blacks than Hispanics or other ethnic groups.

The unique contribution of this study is that it extends previous findings. Some unique advantages include a nationally representative sample, a large sample, and a very long follow-up period. We also applied two statistical approaches to increase the robustness of our findings. While considerable research previously showed MDRs of education and income on a wide range of mental health outcomes, this research mainly involved cross-sectional or short-term follow-up studies. This study was unique in reporting 24 years of depressive symptoms as the outcome.

\subsection{Limitations}

Each study has its limitations. The current study is not an exception to that rule. To list the significant methodological limitations of our study, we can refer to the measurement of depressive symptoms. Depressive symptoms were measured using self-reported data. We also did not control for wealth. Thus, our study was at risk of omitted confounders. This study only included area-level SES indicators. Another limitation was missing confounders such as wealth, income, employment, and marital status. Finally, a limitation in this study was how CES-D response items were applied. While CES-D uses four-item responses, the HRS uses 0/1 responses, which reduces the validity and reliability of the measure.

\subsection{Future Research}

Future data may validate self-reported depressive symptoms using triangulation methods such as clinical diagnosis by a psychiatrist, administrative data, chart review, or claim data. Future research may test if these results can be replicated in other datasets and settings. There is also a need to replicate these findings using other SES indicators. There is a need to test MDRs in other ethnic and racial groups, immigrants, and other marginalized people such as members of the LGBT community.

\section{Conclusions}

In the United States, the inverse associations between education level and burden of depressive symptoms over time are weaker for Hispanic White than non-Hispanic White middle-aged and older Americans. Future research may investigate contextual factors that explain why middle-class ethnic minorities remain at risk of depressive symptoms and poor mental health.

Author Contributions: Publicly available data were used. S.A. conducted the data analysis and prepared the draft. He revised the paper and approved the final draft. All authors have read and agreed to the published version of the manuscript.

Funding: S.A. is supported by the following National Institutes of Health (NIH) funding: 5S21MD000103, U54MD008149, R25 MD007610, U54MD007598, U54 TR001627, CA201415-02, and U54CA229974.

Conflicts of Interest: The author declares no conflicts of interest. 


\section{References}

1. Fischer, C.; Yeung, E.; Hansen, T.; Gibbons, S.; Fornazzari, L.; Ringer, L.; Schweizer, T.A. Impact of socioeconomic status on the prevalence of dementia in an inner city memory disorders clinic. Int. Psychogeriatr. 2009, 21, 1096-1104. [CrossRef]

2. Marden, J.R.; Tchetgen Tchetgen, E.J.; Kawachi, I.; Glymour, M.M. Contribution of Socioeconomic Status at 3 Life-Course Periods to Late-Life Memory Function and Decline: Early and Late Predictors of Dementia Risk. Am. J. Epidemiol. 2017, 186, 805-814. [CrossRef]

3. Brayne, C.; Calloway, P. The association of education and socioeconomic status with the Mini Mental State Examination and the clinical diagnosis of dementia in elderly people. Age Ageing 1990, 19, 91-96. [CrossRef]

4. Chen, N.C.; Liang, C.K.; Yin, C.H.; Lin, Y.T.; Lee, C.C.; Chen, C.L. Effects of Socioeconomic Status on Alzheimer Disease Mortality in Taiwan. Am. J. Geriatr. Psychiatry 2019. [CrossRef]

5. Deckers, K.; Cadar, D.; van Boxtel, M.P.J.; Verhey, F.R.J.; Steptoe, A.; Kohler, S. Modifiable Risk Factors Explain Socioeconomic Inequalities in Dementia Risk: Evidence from a Population-Based Prospective Cohort Study. J. Alzheimer's Dis. 2019, 71, 549-557. [CrossRef]

6. Assari, S. Social Determinants of Depression: The Intersections of Race, Gender, and Socioeconomic Status. Brain Sci. 2017, 7. [CrossRef]

7. Domenech-Abella, J.; Mundo, J.; Miret, M.; Ayuso-Mateos, J.L.; Sanchez-Niubo, A.; Abduljabbar, A.S.; Haro, J.M.; Olaya, B. From childhood financial hardship to late-life depression: Socioeconomic pathways. Aging Ment. Health 2019, 1-8. [CrossRef]

8. Gazmararian, J.A.; James, S.A.; Lepkowski, J.M. Depression in black and white women. The role of marriage and socioeconomic status. Ann. Epidemiol. 1995, 5, 455-463. [CrossRef]

9. Hudson, D.L.; Neighbors, H.W.; Geronimus, A.T.; Jackson, J.S. The relationship between socioeconomic position and depression among a US nationally representative sample of African Americans. Soc. Psychiatry Psychiatr. Epidemiol. 2012, 47, 373-381. [CrossRef]

10. Ruiz, M.; Hu, Y.; Martikainen, P.; Bobak, M. Life course socioeconomic position and incidence of mid-late life depression in China and England: A comparative analysis of CHARLS and ELSA. J. Epidemiol. Community Health 2019, 73, 817-824. [CrossRef]

11. Silvernale, C.; Kuo, B.; Staller, K. Lower socioeconomic status is associated with an increased prevalence of comorbid anxiety and depression among patients with irritable bowel syndrome: Results from a multicenter cohort. Scand. J. Gastroenterol. 2019, 54, 1070-1074. [CrossRef]

12. Fletcher, J.M. Adolescent depression and educational attainment: Results using sibling fixed effects. Health Econ. 2010, 19, 855-871. [CrossRef]

13. Hudson, D.L.; Bullard, K.M.; Neighbors, H.W.; Geronimus, A.T.; Yang, J.; Jackson, J.S. Are benefits conferred with greater socioeconomic position undermined by racial discrimination among African American men? J. Men's Health 2012, 9, 127-136. [CrossRef]

14. Hudson, D.L.; Puterman, E.; Bibbins-Domingo, K.; Matthews, K.A.; Adler, N.E. Race, life course socioeconomic position, racial discrimination, depressive symptoms and self-rated health. Soc. Sci. Med. 2013, 97, 7-14. [CrossRef]

15. Lincoln, K.D.; Taylor, R.J.; Watkins, D.C.; Chatters, L.M. Correlates of Psychological Distress and Major Depressive Disorder Among African American Men. Res. Soc. Work Pract. 2011, 21, 278-288. [CrossRef]

16. Ursache, A.; Merz, E.C.; Melvin, S.; Meyer, J.; Noble, K.G. Socioeconomic status, hair cortisol and internalizing symptoms in parents and children. Psychoneuroendocrinology 2017, 78, 142-150. [CrossRef]

17. Assari, S. Health Disparities due to Diminished Return among Black Americans: Public Policy Solutions. Soc. Issues Policy Rev. 2018, 12, 112-145. [CrossRef]

18. Assari, S. Unequal Gain of Equal Resources across Racial Groups. Int. J. Health Policy Manag. $2018,7,1$. [CrossRef]

19. Assari, S. Parental Education Attainment and Educational Upward Mobility; Role of Race and Gender. Behav. Sci. 2018, 8. [CrossRef]

20. Assari, S. Race, Intergenerational Social Mobility and Stressful Life Events. Behav. Sci. 2018, 8. [CrossRef]

21. Assari, S.; Bazargan, M. Unequal Associations between Educational Attainment and Occupational Stress across Racial and Ethnic Groups. Int. J. Environ. Res. Public Health 2019, 16, 3539. [CrossRef] 
22. Assari, S.; Caldwell, C.H.; Zimmerman, M.A. Family Structure and Subsequent Anxiety Symptoms; Minorities' Diminished Return. Brain Sci. 2018, 8. [CrossRef]

23. Assari, S. The Benefits of Higher Income in Protecting against Chronic Medical Conditions Are Smaller for African Americans than Whites. Healthcare 2018, 6. [CrossRef]

24. Assari, S.; Caldwell, C.H.; Bazargan, M. Association Between Parental Educational Attainment and Youth Outcomes and Role of Race/Ethnicity. JAMA Netw. Open 2019, 2, e1916018. [CrossRef]

25. Assari, S. Educational Attainment Better Protects African American Women than African American Men Against Depressive Symptoms and Psychological Distress. Brain Sci. 2018, 8. [CrossRef]

26. Assari, S. High Income Protects Whites but Not African Americans against Risk of Depression. Healthcare 2018, 6. [CrossRef]

27. Assari, S.; Caldwell, C.H. High Risk of Depression in High-Income African American Boys. J. Racial Ethn. Health Disparities 2018, 5, 808-819. [CrossRef]

28. Assari, S.; Gibbons, F.X.; Simons, R. Depression among Black Youth; Interaction of Class and Place. Brain Sci. 2018, 8. [CrossRef]

29. Assari, S.; Gibbons, F.X.; Simons, R.L. Perceived Discrimination among Black Youth: An 18-Year Longitudinal Study. Behav. Sci. 2018, 8. [CrossRef]

30. Assari, S.; Lankarani, M.M.; Caldwell, C.H. Does Discrimination Explain High Risk of Depression among High-Income African American Men? Behav. Sci. 2018, 8. [CrossRef]

31. Shadlen, M.F.; Siscovick, D.; Fitzpatrick, A.L.; Dulberg, C.; Kuller, L.H.; Jackson, S. Education, cognitive test scores, and black-white differences in dementia risk. J. Am. Geriatr. Soc. 2006, 54, 898-905. [CrossRef]

32. Assari, S. Ethnicity, educational attainment, and physical health of older adults in the United States. Aging Med. (Milton) 2019, 2, 104-111. [CrossRef]

33. Assari, S.; Bazargan, M. Minorities' Diminished Returns of Educational Attainment on Hospitalization Risk: National Health Interview Survey (NHIS). Hosp. Pract. Res. 2019, 4, 86. [CrossRef]

34. Assari, S.; Bazargan, M. Educational Attainment and Self-Rated Oral Health among American Older Adults: Hispanics' Diminished Returns. Dent. J. 2019, 7, 97. [CrossRef]

35. Assari, S.; Preiser, B.; Kelly, M. Education and Income Predict Future Emotional Well-Being of Whites but Not Blacks: A Ten-Year Cohort. Brain Sci. 2018, 8. [CrossRef]

36. Assari, S.; Bazargan, M. Unequal Effects of Educational Attainment on Workplace Exposure to Second-Hand Smoke by Race and Ethnicity; Minorities' Diminished Returns in the National Health Interview Survey (NHIS). J. Med. Res. Innov. 2019, 3, e000179. [CrossRef]

37. Assari, S.; Bazargan, M. Second-hand smoke exposure at home in the United States; minorities' diminished returns. Int. J. Travel Med. Glob. Health 2019, 7, 135. [CrossRef]

38. Assari, S.; Mistry, R.; Bazargan, M. Race, Educational Attainment, and E-Cigarette Use. J. Med. Res. Innov. 2020, 4, e000185. [CrossRef]

39. Assari, S.; Mistry, R. Diminished Return of Employment on Ever Smoking Among Hispanic Whites in Los Angeles. Health Equity 2019, 3, 138-144. [CrossRef]

40. Assari, S.; Bazargan, M. Being Married Increases Life Expectancy of White but Not Black Americans. J. Fam. Reprod. Health 2019, 132-140. [CrossRef]

41. Assari, S. Educational Attainment and Exercise Frequency in American Women; Blacks' Diminished Returns. Women's Health Bull. 2019, 6, e87413. [CrossRef]

42. Assari, S.; Lankarani, M.M. Educational Attainment Promotes Fruit and Vegetable Intake for Whites but Not Blacks. J.-Multidiscip. Sci. J. 2018, 1, 29-41. [CrossRef]

43. Assari, S.; Bazargan, M. Educational Attainment Better Increases the Chance of Breast Physical Exam for Non-Hispanic Than Hispanic American Women: National Health Interview Survey. Hosp. Pract. Res. 2019, 4, 122-127. [CrossRef] [PubMed]

44. Assari, S. Combined Racial and Gender Differences in the Long-Term Predictive Role of Education on Depressive Symptoms and Chronic Medical Conditions. J. Racial Ethn. Health Disparities 2017, 4, 385-396. [CrossRef] [PubMed]

45. Assari, S.; Schatten, H.T.; Arias, S.A.; Miller, I.W.; Camargo, C.A.; Boudreaux, E.D. Higher Educational Attainment is Associated with Lower Risk of a Future Suicide Attempt Among Non-Hispanic Whites but not Non-Hispanic Blacks. J. Racial Ethn. Health Disparities 2019. [CrossRef] 
46. Assari, S.; Farokhnia, M.; Mistry, R. Education Attainment and Alcohol Binge Drinking: Diminished Returns of Hispanics in Los Angeles. Behav. Sci. 2019, 9. [CrossRef] [PubMed]

47. Assari, S. Life Expectancy Gain Due to Employment Status Depends on Race, Gender, Education, and Their Intersections. J. Racial Ethn. Health Disparities 2018, 5, 375-386. [CrossRef]

48. Assari, S.; Bazargan, M. Educational Attainment Better Reduces Disability for Non-Hispanic than Hispanic Americans. Eur. J. Investig. Health Psychol. Educ. 2019, 10, 10-17. [CrossRef]

49. Apolinario, D.; Mansur, L.L.; Carthery-Goulart, M.T.; Brucki, S.M.; Nitrini, R. Cognitive predictors of limited health literacy in adults with heterogeneous socioeconomic backgrounds. J. Health Psychol. 2015, 20, 1613-1625. [CrossRef]

50. Silverberg, N.D.; Hanks, R.A.; Tompkins, S.C. Education quality, reading recognition, and racial differences in the neuropsychological outcome from traumatic brain injury. Arch. Clin. Neuropsychol. 2013, 28, 485-491. [CrossRef]

51. Sisco, S.; Gross, A.L.; Shih, R.A.; Sachs, B.C.; Glymour, M.M.; Bangen, K.J.; Benitez, A.; Skinner, J.; Schneider, B.C.; Manly, J.J. The role of early-life educational quality and literacy in explaining racial disparities in cognition in late life. J. Gerontol. B Psychol. Sci. Soc. Sci. 2015, 70, 557-567. [CrossRef]

52. Zajacova, A.; Lawrence, E.M. The Relationship between Education and Health: Reducing Disparities Through a Contextual Approach. Annu. Rev. Public Health 2018, 39, 273-289. [CrossRef]

53. Manly, J.J.; Byrd, D.A.; Touradji, P.; Stern, Y. Acculturation, reading level, and neuropsychological test performance among African American elders. Appl. Neuropsychol. 2004, 11, 37-46. [CrossRef]

54. Manly, J.J.; Jacobs, D.M.; Touradji, P.; Small, S.A.; Stern, Y. Reading level attenuates differences in neuropsychological test performance between African American and White elders. J. Int. Neuropsychol. Soc. 2002, 8, 341-348. [CrossRef]

55. Manly, J.J.; Touradji, P.; Tang, M.X.; Stern, Y. Literacy and memory decline among ethnically diverse elders. J. Clin. Exp. Neuropsychol. 2003, 25, 680-690. [CrossRef]

56. Zahodne, L.B.; Manly, J.J.; Smith, J.; Seeman, T.; Lachman, M.E. Socioeconomic, health, and psychosocial mediators of racial disparities in cognition in early, middle, and late adulthood. Psychol. Aging 2017, 32, 118-130. [CrossRef]

57. Assari, S. Family Socioeconomic Position at Birth and School Bonding at Age 15; Blacks' Diminished Returns. Behav. Sci. 2019, 9. [CrossRef]

58. Assari, S. Parental Educational Attainment and Mental Well-Being of College Students; Diminished Returns of Blacks. Brain Sci. 2018, 8. [CrossRef]

59. Assari, S. Parental Educational Attainment and Academic Performance of American College Students; Blacks' Diminished Returns. J. Health Econ. Dev. 2019, 1, 21-31.

60. Assari, S.; Bazargan, M. Educational attainment and tobacco harm knowledge among American adults: Diminished returns of African Americans and Hispanics. Int. J. Epidemiol. Res. 2020, 7. [CrossRef]

61. Assari, S. Parental Education Better Helps White than Black Families Escape Poverty: National Survey of Children's Health. Economies 2018, 6, 30. [CrossRef]

62. Assari, S. Blacks' Diminished Return of Education Attainment on Subjective Health; Mediating Effect of Income. Brain Sci. 2018, 8. [CrossRef] [PubMed]

63. Assari, S. Association of Educational Attainment and Race/Ethnicity with Exposure to Tobacco Advertisement among US Young Adults. JAMA Netw. Open 2020, 3, e1919393. [CrossRef] [PubMed]

64. Hudson, D.L.; Neighbors, H.W.; Geronimus, A.T.; Jackson, J.S. Racial Discrimination, John Henryism, and Depression among African Americans. J. Black Psychol. 2016, 42, 221-243. [CrossRef]

65. Assari, S.; Preiser, B.; Lankarani, M.M.; Caldwell, C.H. Subjective Socioeconomic Status Moderates the Association between Discrimination and Depression in African American Youth. Brain Sci. 2018, 8. [CrossRef]

66. Assari, S. Does School Racial Composition Explain Why High Income Black Youth Perceive More Discrimination? A Gender Analysis. Brain Sci. 2018, 8. [CrossRef]

67. Assari, S.; Moghani Lankarani, M. Workplace Racial Composition Explains High Perceived Discrimination of High Socioeconomic Status African American Men. Brain Sci. 2018, 8. [CrossRef]

68. Maharani, A. Childhood Socioeconomic Status and Cognitive Function Later in Life: Evidence from a National Survey in Indonesia. J. Geriatr. Psychiatry Neurol. 2019. [CrossRef] 
69. Zeki Al Hazzouri, A.; Haan, M.N.; Galea, S.; Aiello, A.E. Life-course exposure to early socioeconomic environment, education in relation to late-life cognitive function among older Mexicans and Mexican Americans. J. Aging Health 2011, 23, 1027-1049. [CrossRef]

70. Assari, S.; Lankarani, M.M. Race and Urbanity Alter the Protective Effect of Education but not Income on Mortality. Front. Public Health 2016, 4, 100. [CrossRef]

71. Assari, S. Diminished economic return of socioeconomic status for black families. Soc. Sci. 2018, 7, 74. [CrossRef]

72. Sonnega, A.; Faul, J.D.; Ofstedal, M.B.; Langa, K.M.; Phillips, J.W.; Weir, D.R. Cohort Profile: The Health and Retirement Study (HRS). Int. J. Epidemiol. 2014, 43, 576-585. [CrossRef]

73. Mirowsky, J.; Ross, C.E. Education, Health, and the Default American Lifestyle. J. Health Soc. Behav. 2015, 56, 297-306. [CrossRef] [PubMed]

74. Ross, C.E.; Mirowsky, J. Refining the association between education and health: The effects of quantity, credential, and selectivity. Demography 1999, 36, 445-460. [CrossRef]

75. Ross, C.E.; Mirowsky, J. The interaction of personal and parental education on health. Soc. Sci. Med. 2011, 72, 591-599. [CrossRef] [PubMed]

76. Horvat, P.; Richards, M.; Malyutina, S.; Pajak, A.; Kubinova, R.; Tamosiunas, A.; Pikhart, H.; Peasey, A.; Marmot, M.G.; Bobak, M. Life course socioeconomic position and mid-late life cognitive function in Eastern Europe. J. Gerontol. B Psychol. Sci. Soc. Sci. 2014, 69, 470-481. [CrossRef] [PubMed]

77. Singh-Manoux, A.; Richards, M.; Marmot, M. Socioeconomic position across the lifecourse: How does it relate to cognitive function in mid-life? Ann. Epidemiol. 2005, 15, 572-578. [CrossRef] [PubMed]

78. Assari, S. Cross-Country Differences in the Additive Effects of Socioeconomics, Health Behaviors and Medical Comorbidities on Disability among Older Adults with Heart Disease. J. Tehran Univ. Cent. 2015, 10, $24-33$.

79. Kim, J.; Kim, Y.S.; Kim, K.; Oh, Y.M.; Yoo, K.H.; Rhee, C.K.; Lee, J.H. Socioeconomic impact of asthma, chronic obstructive pulmonary disease and asthma-COPD overlap syndrome. J. Thorac. Dis. 2017, 9, 1547-1556. [CrossRef]

80. Kunst, A.E.; Groenhof, F.; Mackenbach, J.P.; Health, E.W. Occupational class and cause specific mortality in middle aged men in 11 European countries: Comparison of population based studies. EU Working Group on Socioeconomic Inequalities in Health. BMJ 1998, 316, 1636-1642. [CrossRef]

81. Packard, C.J.; Bezlyak, V.; McLean, J.S.; Batty, G.D.; Ford, I.; Burns, H.; Cavanagh, J.; Deans, K.A.; Henderson, M.; McGinty, A.; et al. Early life socioeconomic adversity is associated in adult life with chronic inflammation, carotid atherosclerosis, poorer lung function and decreased cognitive performance: A cross-sectional, population-based study. BMC Public Health 2011, 11, 42. [CrossRef] [PubMed]

82. Prescott, E.; Lange, P.; Vestbo, J. Socioeconomic status, lung function and admission to hospital for COPD: Results from the Copenhagen City Heart Study. Eur. Respir. J. 1999, 13, 1109-1114. [CrossRef]

83. Prescott, E.; Vestbo, J. Socioeconomic status and chronic obstructive pulmonary disease. Thorax 1999, 54, 737-741. [CrossRef]

84. Navarro, V. Race or class or race and class: Growing mortality differentials in the United States. Int. J. Health Serv. 1991, 21, 229-235. [CrossRef]

85. Navarro, V. Race or class versus race and class: Mortality differentials in the United States. Lancet 1990, 336, 1238-1240. [CrossRef]

86. Navarro, V. Race or class, or race and class. Int. J. Health Serv. 1989, 19, 311-314. [CrossRef]

87. Farmer, M.M.; Ferraro, K.F. Are racial disparities in health conditional on socioeconomic status? Soc. Sci. Med. 2005, 60, 191-204. [CrossRef]

88. Assari, S.; Lapeyrouse, L.M.; Neighbors, H.W. Income and Self-Rated Mental Health: Diminished Returns for High Income Black Americans. Behav. Sci. 2018, 8. [CrossRef]

89. Assari, S.; Caldwell, C.H.; Mincy, R. Family Socioeconomic Status at Birth and Youth Impulsivity at Age 15; Blacks' Diminished Return. Children 2018, 5. [CrossRef]

90. Assari, S.; Lankarani, M.M. Education and Alcohol Consumption among Older Americans; Black-White Differences. Front. Public Health 2016, 4, 67. [CrossRef]

91. Assari, S.; Mistry, R. Educational Attainment and Smoking Status in a National Sample of American Adults; Evidence for the Blacks' Diminished Return. Int. J. Environ. Res. Public Health 2018, 15. [CrossRef]

92. Assari, S.; Chalian, H.; Bazargan, M. Race, ethnicity, socioeconomic status, and chronic lung disease in the U.S. Res. Health Sci. 2020, 5, 48-63. [CrossRef] 
93. Assari, S.; Nikahd, A.; Malekahmadi, M.R.; Lankarani, M.M.; Zamanian, H. Race by gender group differences in the protective effects of socioeconomic factors against sustained health problems across five domains. J. Racial Ethn. Health Disparities 2017, 4, 884-894. [CrossRef]

94. Assari, S. Socioeconomic Determinants of Systolic Blood Pressure; Minorities' Diminished Returns. J. Health Econ. Dev. 2019, 1, 1.

95. Assari, S. Family Income Reduces Risk of Obesity for White but Not Black Children. Children $2018,5$. [CrossRef]

96. Assari, S.; Moghani Lankarani, M. Poverty Status and Childhood Asthma in White and Black Families: National Survey of Children's Health. Healthcare 2018, 6. [CrossRef]

97. Assari, S.; Boyce, S.; Bazargan, M.; Caldwell, C.H. Mathematical performance of American youth: Diminished returns of educational attainment of Asian-American parents. Educ. Sci. 2020, 10, 32. [CrossRef]

98. Assari, S. Diminished returns of income against cigarette smoking among Chinese Americans. J. Health Econ. Dev. 2019, 1, 1.

99. Assari, S.; Bazargan, M. Education Level and Cigarette Smoking: Diminished Returns of Lesbian, Gay and Bisexual Individuals. Behav. Sci. 2019, 9. [CrossRef]

(C) 2020 by the author. Licensee MDPI, Basel, Switzerland. This article is an open access article distributed under the terms and conditions of the Creative Commons Attribution (CC BY) license (http://creativecommons.org/licenses/by/4.0/). 